\title{
Identification of novel Bach2 transcripts and protein isoforms through tagging analysis of retroviral integrations in B-cell lymphomas \\ Jinghua Liu ${ }^{1}$, Annette Balle Sørensen ${ }^{2}$, Bruce Wang ${ }^{3}$, Matthias Wabl ${ }^{4}$, Anders Lade Nielsen ${ }^{5}$ and Finn Skou Pedersen*6
}

\author{
Address: ${ }^{1}$ Department of Molecular Biology, University of Aarhus, Aarhus, DK 8000, Denmark, ${ }^{2}$ The State and University Library, Aarhus, DK \\ 8000, Denmark, ${ }^{3}$ Picobella, L.L.C, 863 Mitten Road, Suite 101, Burlingame, CA 94010, USA, ${ }^{4}$ Department of Microbiology and Immunology, \\ University of California, San Francisco, CA-94143, USA, ${ }^{5}$ Department of Human Genetics, University of Aarhus, Aarhus, DK 8000, Denmark and \\ ${ }^{6}$ Department of Molecular Biology, C.F. Møllers Allé 1.130, University of Aarhus, DK-8000 Aarhus C, Denmark \\ Email: Jinghua Liu - jul@mb.au.dk; Annette Balle Sørensen - abs@statsbiblioteket.dk; Bruce Wang - bruce@picobella.com; \\ Matthias Wabl - mutator@ucsf.edu; Anders Lade Nielsen - aln@humgen.au.dk; Finn Skou Pedersen* - fsp@mb.au.dk \\ * Corresponding author
}

Published: 21 January 2009

BMC Molecular Biology 2009, 10:2 doi:10.1 186/1471-2199-10-2

This article is available from: http://www.biomedcentral.com/I47/-2199//0/2

(c) 2009 Liu et al; licensee BioMed Central Ltd.

This is an Open Access article distributed under the terms of the Creative Commons Attribution License (http://creativecommons.org/licenses/by/2.0), which permits unrestricted use, distribution, and reproduction in any medium, provided the original work is properly cited.
Received: 12 August 2008

Accepted: 21 January 2009

\begin{abstract}
Background: The Bach2 gene functions as a transcriptional repressor in B-cells, showing high expression level only before the plasma cell stage. Several lines of evidence indicate that Bach2 is a B-cell specific tumor suppressor. We here address patterns of insertional mutagenesis and expression of Bach2 is a murine retroviral model of B-cell lymphoma induction.

Results: We report that the Bach2 gene is a target of proviral integrations in B-cell lymphomas induced by murine leukemia virus. An alternative Bach2 promoter was identified within intron 2 and this promoter was activated in one of the tumors harboring proviral integration. The alternative promoter was active in both normal and tumor tissue and the tissue specificity of the two Bach2 promoters was similar. Three different alternatively used Bach2 terminal exons were identified to be located in intron 4. The inclusion of these exons resulted in the generation of Bach2 mRNA with open reading frames lacking the bZIP DNA binding domain present in the normal Bach2 protein, but retaining a partial BTB protein dimerization domain. Such Bach2 protein was excluded from the cell nucleus.

Conclusion: We have identified an alternative promoter and new protein isoforms of Bach2. Our data imply that activation of an alternative promoter by proviral integration serves as a possible mechanism of up-regulation of the Bach2 gene with a potential role in B-cell lymphomagenesis. The finding of novel Bach2 transcripts and protein isoforms will facilitate a better insight into the normal and pathophysiological regulation of the Bach2 gene.
\end{abstract}

\section{Background}

The transcription factor Bach2 (BTB and CNC homolog 2) is a member of the family of proteins harboring a basic region leucine zipper (bZip) DNA binding domain [1]. In addition, Bach2 possesses a BTB domain. Both of these domains are involved in forming heterologous protein- 
protein interactions [2-4]. In mice abundant Bach2 expression is described in neuronal cells, monocytes, and in the B-cell compartment only before the plasma cell stage $[1,5,6]$. The sub-cellular localization of the Bach2 protein is controlled by the cytoplasmic localization signal present in the bZip domain and a C-terminal nuclearexport signal. Bach2 is localized in the cytoplasm through its C-terminal nuclear export signal [7]. In B-cells, phosphorylation of Bach 2 by the PI3/S6 kinase pathway results in the cytoplasmic accumulation of Bach2 [8]. Nuclear accumulation of Bach2 is induced by anticancer drugs with oxidative stress activities and is regulated by small ubiquitin like modifier-1 or by SUMOylation $[9,10]$. Bach2 nuclear foci are observed to be associated with promyelocytic leukemia nuclear bodies in apoptosis [11].

Bach2 proteins function as transcriptional repressors and form heterodimers with small Maf oncoproteins (MafF, MafG, MafK). Such heterodimers bind to the Maf recognition elements [1]. As an example, Bach2 negatively regulates the immunoglobulin heavy chain gene by binding to the Maf recognition element in the 3'-enhancer [6]. Besides, Bach2 is crucial for the programming of antibody class switching and somatic hypermutation of immunoglobulin genes [12]. Several lines of evidence show that Bach2 is a B-cell specific tumor suppressor. For example, in non Hodgkin's Lymphoma, a relatively high frequency of loss of heterozygosity was detected for Bach2 [13]. Moreover, the Bach2 expression level has proven to be a useful marker to predict disease-free and overall survival of patients with diffuse large B-cell lymphoma, where a favorable prognosis is correlated with a high expression level of Bach2 [14]. In consistence with its role as a putative tumor suppressor, Bach2 was found to induce apoptosis in response to oxidative stress [7]. Over-expression of Bach2 increased cellular toxicity of anticancer drugs that generate reactive oxygen species [9]. In the Burkitt lymphoma cell line Raji, loss of Bach2 expression at both the mRNA and protein levels was attributed to Epstein-Barr virus (EBV) genome integration into the host Bach2 gene [15]. The enforced expression of Bach2 in the Raji cell line led to a marked reduction of clonogenity [13]. Moreover, Bach2 was seen down-regulated in proliferating lymphoblastoid cell lines, which were in vitro transformed by EBV from resting B-cells [16]. These findings suggest that loss or down-regulation of Bach2 expression may contribute to B-cell lymphomagenesis.

Proviral insertional mutagenesis plays an important role in lymphomagenesis by non-acutely transforming murine leukemia viruses (MLVs). By insertion of proviral DNA into the host genome, the retrovirus may activate cellular proto-oncogenes, or more rarely repress tumour suppressor genes [17-19]. Thus, loci or genes repeatedly found to be targeted in retrovirus-induced tumors most likely play important roles in the disease process. The specific genes that are tagged by a provirus in a given retrovirus-induced tumor depend on virus type as well as on mouse genetic background $[20,21]$.

In the present study we have examined tumors induced by wild-type and mutants of Akv MLV in inbred NMRI mice. In these models the tumors are of B-cell lineage with frequent occurrence of plasmacytomas/plasma cell proliferation [22-24]. Recently, we proposed that polyclonal immune stimulation and insertional mutagenesis exert dual effects in the process of disease induction in this $\mathrm{Akv} /$ inbred-NMRI model [23]. We here describe the Bach2 locus as a prominent target in MLV induced B-cell lymphogenesis. A cluster of integrations was detected in intron 2 of the Bach 2 gene. Interestingly, in the same intron we have identified an alternative Bach2 promoter. We also identified alternatively used Bach 2 terminal exons located within intron 4. Utilization of alternative promoter sequences and terminal exons resulted in new Bach2 mRNA subtypes, of which several have coding potential for Bach2 protein isoforms containing a partial BTB protein-protein interaction domain but lacking the bZIP DNA binding domain. Altogether, the presented data show a novel regulatory complexity resulting in the generation of different Bach2 proteins.

\section{Methods}

\section{Mouse tumors and tissues}

Tumors used in this study were induced in NMRI inbred mice by Akv MLV variants from previous and unpublished work $[22,24,25]$. In brief, infectious viral particles of Akv MLV and derivatives hereof were inoculated into newborn inbred NMRI mice. Upon diagnosis of lymphomas, the animals were sacrificed and lymphomas were dissected and frozen (criteria for diagnosis were described previously [26]). Tissues from mock-injected or untreated mice served as controls. All animal studies were in accordance with the German Animal Welfare Act. They were approved by the Institutional Animal Care and Use Committee (IACUC) of the Helmholtz Center Munich and by the ethical committee of the Government of Upper Bavaria, Germany (211-2531-48/98 and 55.2-1-54-2531-98-03).

\section{Genomic DNA and total RNA Isolation and Quantification} Genomic DNA and total RNA were isolated from frozen tumors and tissues using DNeasy Tissue Kit (Qiagen) and TRIzol $^{\circledR}$ Reagent (Invitrogen ${ }^{\mathrm{TM}}$ ), respectively. Quantification was performed by a spectrophotometer.

\section{PCR identification and verification of provirus integration sites}

Genomic DNA isolated from the induced tumors was analyzed for provirus integration sites by a splinkerette-based PCR method [27] described in details elsewhere [28]. To confirm provirus integrations into the Bach2 gene, PCR were done on genomic DNA from tumors with a gene spe- 
cific primer and a viral primer. The gene specific primers at different proviral integration sites were designed according to integration site data. Viral primers 2620 or 6197 were both described previously $[22,29]$. The PCR was run in a $25-\mu$ l volume containing $0.625 \mathrm{U}$ of Taq DNA polymerase ( $5 \mathrm{U} / \mu \mathrm{l}$; Invitrogen), $1.5 \mathrm{mM} \mathrm{MgCl}_{2}$ (Invitrogen), $2.5 \mu \mathrm{l}$ of $10 \times \mathrm{Taq}$ buffer (Invitrogen), $0.2 \mathrm{mM}$ of each deoxynucleoside triphosphate (Invitrogen), and 10 pmol of each primer. The fragments were amplified in a 2720 thermal cycler (Applied Biosystems) with a touchdown program as follows: 1 cycle of denaturation at $94^{\circ} \mathrm{C}$ for $5 \mathrm{~min}$ and then 10 cycles of denaturation at $94^{\circ} \mathrm{C}$ for $30 \mathrm{~s}$, annealing at $64-55^{\circ} \mathrm{C}$ for $30 \mathrm{~s}$ with 1 cycle decreasing $1^{\circ} \mathrm{C}$, and extension at $72^{\circ} \mathrm{C}$ for $3 \mathrm{~min}$ followed by 30 cycles of denaturation at $94^{\circ} \mathrm{C}$ for $30 \mathrm{~s}$, annealing at $55^{\circ} \mathrm{C}$ for $30 \mathrm{~s}$, and extension at $72^{\circ} \mathrm{C}$ for $3 \mathrm{~min}$, and finally 1 cycle of extension at $72^{\circ} \mathrm{C}$ for $10 \mathrm{~min}$.

\section{Southern blot analyses}

Twenty micrograms of genomic DNA from each sample was digested with HindIII or NcoI, separated on a $0.8 \%$ agarose gel, transferred to a Zeta-Probe membrane (BioRad), and hybridized with ${ }^{32} \mathrm{P}$ labelled Bach2 specific DNA probes or an ecotropic MLV-specific envelope probe (Eco-env). The Bach2 gene-specific DNA probes were PCR products of $892 \mathrm{bp}$ or $743 \mathrm{bp}$, amplified with the following primer pairs: probe1; 5'-TCTAGGGTTCAGGTGGGATG-3' and 5'-GCACAAGTGCTGGCTAACAA-3'; probe2; 5'-ACTTCAGGCTACTGCCCAGA-3' and 5'CACATGGAGACGGTTGTGAC-3'. Probes were purified from gel bands with GFX columns. The Eco-env probe and detailed procedures for blotting and hybridization were described previously $[22,30]$.

\section{RT-PCR, Q-PCR, and sequencing}

For generation of RT-PCR templates first-strand CDNA was synthesized from $200 \mathrm{ng}$ total RNA with an oligo dT primer kit (GE Healthcare) and for experiments comparing oligo dT primed and random-primed cDNA synthesis with the RevertAid H Minus First Strand cDNA Synthesis Kit (Fermentas). RT-PCR reactions were performed with the following program: 1 cycle of denaturation at $94^{\circ} \mathrm{C}$ for $5 \mathrm{~min}$ and then 40 cycles of denaturation at $94^{\circ} \mathrm{C}$ for $30 \mathrm{~s}$, annealing at $60^{\circ} \mathrm{C}$ for $30 \mathrm{~s}$ and extension at $72^{\circ} \mathrm{C}$ for $3 \mathrm{~min}$, and finally 1 cycle of extension at $72^{\circ} \mathrm{C}$ for $10 \mathrm{~min}$. PCR products were separated by agarose gel electrophoresis and purified with GFX columns before subjected to sequence determination by ABI 7300 Biosystems. Quantitative real-time RT-PCR (Q-PCR) was performed on a MX4000 ${ }^{\mathrm{TM}}$ Multiplex Quantitative PCR system (Stratagene) or on a lightcycler (Roche). For each reaction, firststrand cDNA from 20 ng of total RNA was used. All reactions were done in triplicates. The amplification efficiencies of Bach 2 amplicons were calculated by the use of standard curve analysis where the Q-PCR templates were serial dilutions of purified Bach2 cDNA derived from spleen and tumor tissue. Bach2 mRNA expression levels were normalized to the expression level for tbp (TATA-box binding protein). Detailed information concerning primer sequences is available upon request.

\section{5'-Rapid amplification of CDNA end (RACE) analyses}

The 5 ' sequences of Bach 2 isoforms were determined by 5 ' RACE analyses using SMART ${ }^{\mathrm{TM}}$ RACE cDNA Amplification kit (Clontech) according to the manufacturer's instructions with slight alterations. Briefly, the 5' RACE-ready cDNA was synthesized with $1 \mu \mathrm{g}$ of total RNA from the mouse tumor ID:99-1206. The 5' sequences were then amplified with the forward universal primer mix (UPM, Clontech) and two Bach2 isofom B specific reverse primers $1 \mathrm{e}$ and $1 \mathrm{f}$, respectively. The primer sequences were as follows: 1e, 5'GTGGCTATGATCCAGTCACCCCGATCT3'; and 1f, 5'-ATGAGTGTTGCACACCGTGAATCTCCTG3'. RACE PCR was performed with the following program: 1 cycle of denaturation at $94^{\circ} \mathrm{C}$ for $5 \mathrm{~min}$ and then 35 cycles of denaturation at $94^{\circ} \mathrm{C}$ for $30 \mathrm{~s}$, annealing at $68^{\circ} \mathrm{C}$ for $30 \mathrm{~s}$, and extension at $72^{\circ} \mathrm{C}$ for $3 \mathrm{~min}$, and finally 1 cycle of extension at $72^{\circ} \mathrm{C}$ for $10 \mathrm{~min}$. RACE products were sequenced by means of ABI 7300 Biosystems with primers UPM, 1e, 1f and another two nested gene-specific primers 1b, 5'-ACGCACACACACTCCACACCCTGAAAG3', and 1c, 5'-ACACGCACACACACTCCACACCCTGAAA$3^{\prime}$, respectively.

\section{Cell culture, transfection and immunofluorescence staining}

NIH 3T3 murine fibroblasts and HEK 293T human embryonic kidney cell line were cultured at $37^{\circ} \mathrm{C}$ with $5 \%$ $\mathrm{CO}_{2}$ in Dulbecco's modified Eagle's medium containing Glutamax-I (Gibco) supplemented with 10\% newborn calf serum or foetal bovine serum, respectively, and with $100 \mathrm{U} / \mathrm{ml}$ penicillin and $100 \mu \mathrm{g} / \mathrm{ml}$ streptomycin. Transfections of NIH 3T3 cells were performed using Lipofectamine Reagent (Invitrogen) following the manufacturer's protocol. HEK 293 T cells were transfected by the calcium phosphate precipitation method [31] using $0.5 \mu \mathrm{g} / \mathrm{cm}^{2}$ DNA. Forty-eight hours after transfection, cells were fixed by para-formaldehyde, immunostained with anti-FLAG antibody and with TRITCconjugated secondary antibody, mounted with DAPImounting solution (Invitrogen), and subjected to fluorescence monitoring by epi-fluorescence microscopy.

\section{Protein extraction and Western Blot analyses}

Protein samples were extracted from frozen tumors or cultured cells $48 \mathrm{~h}$ post-transfection with lysis buffer $(50 \mathrm{mM}$ Tris-HCl (pH 8.0), $150 \mathrm{mM} \mathrm{NaCl}, 1 \% \mathrm{NP}-40,0.5 \%$ sodium deoxycholate, $0.1 \%$ SDS and $1 \mathrm{mM}$ PMSF). Samples containing $10 \mu \mathrm{g}$ total protein $\left(\mathrm{BCA}^{\mathrm{TM}}\right.$ Protein Assay Kit, Pierce Biotechnology) were resolved on a $12.5 \%$ SDSPAGE gel and electro-transferred onto a polyvinylidene fluoride (PVDF) membrane (Millipore Corporation). The 
membrane was blocked in TBS (20 mM Tris-HCl, $200 \mathrm{mM}$ $\mathrm{NaCl}, \mathrm{pH} 7.6)$ containing $0.05 \%$ Tween-20 (TBS-T) and $5 \%(\mathrm{w} / \mathrm{v})$ fat-free milk. The blot was hybridized for $1 \mathrm{~h}$ with goat anti-mouse Bach2 polyclonal antibody against the N-terminus of the Bach2 protein (sc-14702) (Santa Cruz Biotechnology) in dilution of 1:1000 in TBS-T containing 5\% fat free milk. The blot was washed twice in TBS-T and then incubated with secondary antibody of horseradish peroxidase (HRP)-conjugated rabbit antigoat immunoglobulins/HRP (DAKO) with 1:5000 dilutions in TBS-T containing 5\% fat-free milk. The membrane was washed twice in TBS and subjected to Bach2 protein detection by ECL Plus Western Blotting Detection System (GE Healthcare) before being exposed to a medical film (Konica Minolta Medical and Graphic Inc.). The membrane was stripped and re-hybridized with 1:5000 dilutions of goat polyclonal anti-human Beta-Actin antibody (sc-1616) (Santa Cruz Biotechnology) for protein loading control. Protein samples extracted from transfected cells were analyzed by Western blots using antiFLAG M2 peroxidase-conjugated monoclonal antibody (Sigma) according to the recommended procedure but using a 1:5000 dilution of antibody.

\section{Results \\ Identification of 18 provirus integrations into the Bach2 locus}

In inbred NMRI mice, wild-type and mutants of Akv MLV induce tumors of B-cell lineage with frequent occurrence of plasmacytomas/plasma cell proliferation [22-24]. To identify cellular genes involved in the disease process provirus integration sites were mapped in dissected tumors.
Out of approximately 2000 identified integration sites 18 were by PCR confirmed to map to the Bach2 locus (Figure 1 and Table 1). Since proviral insertion into the host genome is essentially a random event, such a frequent observation of proviruses within the Bach2 locus strongly supports a role in lymphomagenesis of the Bach2 gene. As shown in Figure 1 and Table 1, the proviruses were integrated in the non-coding region; two were located within the promoter region; six within intron 1 ; seven within intron 2; and three within intron 3. All but three integrated proviruses were inserted in opposite orientation relative to the transcriptional orientation of Bach2.

In order to clarify if the identified provirus integrations were present in a large fraction of cells in their respective tumors, we performed Southern Blot analyses on tumor genomic DNA. We did not observe any rearrangement of genomic DNA, corresponding to provirus integrations, using Bach2 gene specific probes (data not shown). Rehybridization with a provirus-specific ecotropic envelope probe confirmed this observation, since no hybridizing fragments were detected (data not shown). Tissues from Balb/c mice containing a single endogenous ecotropic provirus were used as positive controls (data not shown). Together this indicated that only a minor proportion of the cells contained the actual proviral integration in endstage tumor tissue.

\section{Examination of the Bach2 mRNA expression level in tumors}

To estimate Bach2 expression levels in tumors quantitative real-time RT-PCR (Q-PCR) was carried out on cDNA from

Table I: Summary of proviral integration in NMRI-i mice into the Bach2 gene

\begin{tabular}{|c|c|c|c|c|c|c|}
\hline No. & Mouse ID & Virus variant ${ }^{\mathrm{a}}$ & Region & Orientation $^{\mathrm{b}}$ & $\mathrm{PCR}^{\mathrm{c}}$ & Southern blots ${ }^{d}$ \\
\hline SI & $03-655$ & Akv I-99Runx & 5' promoter & - & + & - \\
\hline S2 & $99-64$ & Akv PBS-Gln & 5 ' promoter & - & + & - \\
\hline S3 & $99-148$ & Akv PBS-Gln & Intron I & - & + & - \\
\hline S4 & $01-1124$ & Akv 1-99mRunx+Egre & IntronI & + & + & n.d. \\
\hline S5 & $98-1286$ & Akv PBS-Gln & Intron I & - & + & n.d. \\
\hline S6 & $99-97$ & Akv PBS-Gln & Intron I & - & + & - \\
\hline S7 & $0 \mathrm{I}-454$ & Akv I-99wt & Intron I & - & + & - \\
\hline S8 & $98-1197$ & Akv PBS-Pro & Intron I & - & + & - \\
\hline S9 & $99-955$ & Akv I-99wt & Intron2 & - & + & - \\
\hline SIO & $99-1020$ & Akv I-99wt & Intron2 & - & + & - \\
\hline SII & $99-1206$ & Akv I-99wt & Intron2 & - & + & - \\
\hline $\mathrm{SI} 2$ & $03-858$ & Akv I-99mGR & Intron2 & - & + & - \\
\hline $\mathrm{SI} 3$ & $99-128$ & Akv PBS-Lys & Intron2 & - & + & - \\
\hline $\mathrm{SI} 4$ & $99-128$ & Akv PBS-Lys & Intron2 & - & + & - \\
\hline SI5 & $03-653$ & Akv I-99mEgre & Intron2 & - & + & - \\
\hline SI6 & $99-74$ & Akv PBS-Gln & Intron3 & + & + & - \\
\hline SI7 & $03-290$ & Akv/SL3-3 TM & Intron3 & + & + & n.d. \\
\hline S18 & $99-95$ & Akv PBS-Arg & Intron3 & - & + & - \\
\hline
\end{tabular}

aThe virus variants originated from our published $[22,24,25,30,56-60]$ or unpublished pathogenicity work. bThe virus was transcribed in the same $(+)$ or opposite (-) orientation compared to that of the mouse Bach2 gene. cProvirus was detectable (+) or undetectable (-) by PCR. dSouthern blots showed the proviral integration to be present in a minor fraction of cells in tumor tissue (-). N.d., not determined. 
A

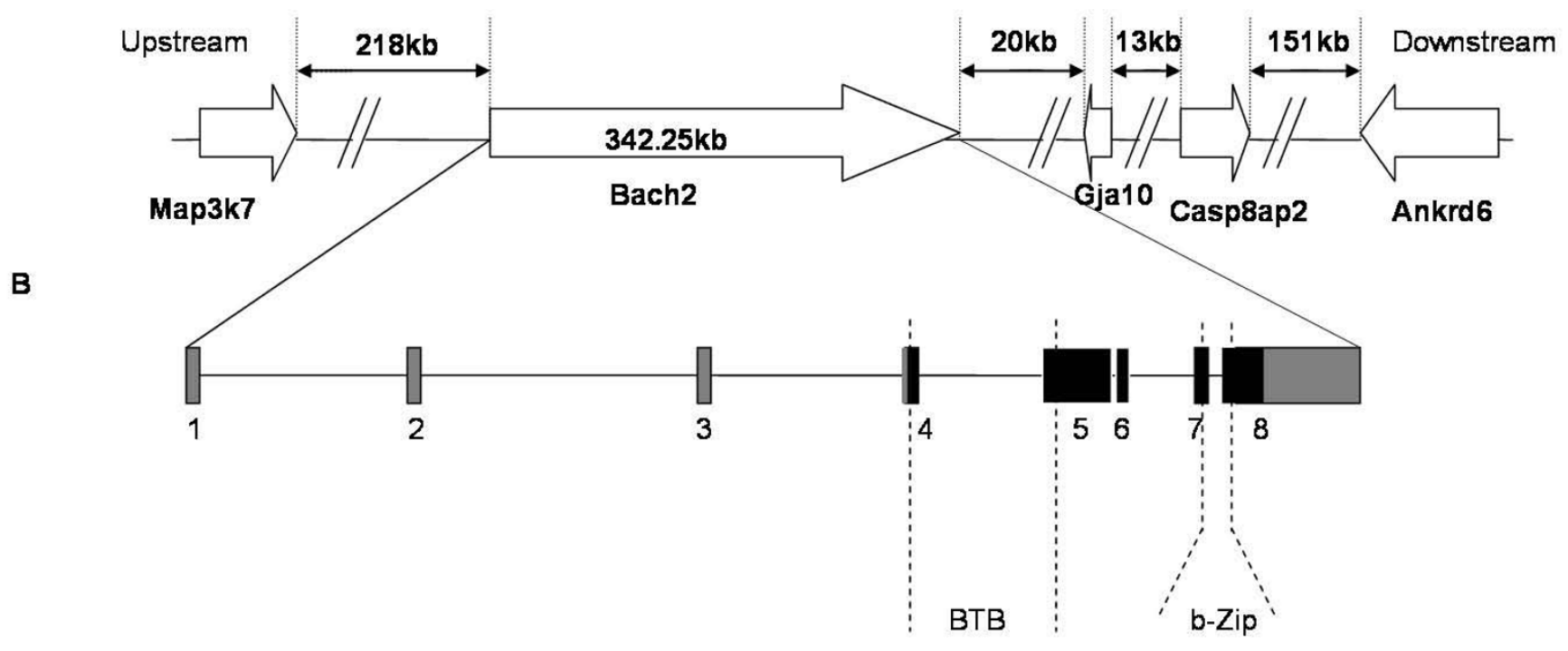

C

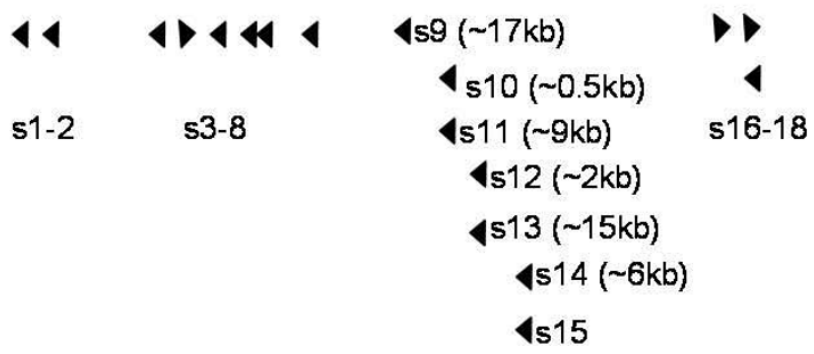

Figure I

The Bach2 locus and proviral integration sites. Structures of genes, exons, and distances between insertion sites are not shown in scale. (A) Schematic description of the mouse chromosome 4 region around the Bach2 locus. The transcriptional orientation of the genes is indicated by arrows. (B) Illustration of the Bach2 gene. The exons are shown with solid bars, with untranslated regions in grey and the coding sequences in black. The dashed lines indicate the location of Bach2 protein domains, BTB and bZip. (C) Illustration of the localization of proviral insertions in the Bach2 gene. Position and transcriptional orientation of the proviruses are shown by triangles and were confirmed by gene-specific PCRs. The proviruses are named after the integration order from left to right at the locus, with $s \mid$ being the first integration site and s 8 the last. For the proviruses located in intron 2, distances away from the nearest upstream proviral integration site are shown in brackets in base pairs.

tumors with provirus insertion in the Bach2 locus. As controls, tumors with no Bach2 locus integration were included together with normal spleen tissue. Using a primer combination spanning Bach2 exons 2 to 3 we observed no significant difference in the Bach2 expression level between the two types of tumor cohorts (Figure 2A). We notice a lower level of Bach2 mRNA expression in all tumor samples compared to the normal spleen control (Figure 2). Using a primer pair covering exons 7 to 8 , we noticed the same tendency, except for tumor 1206, which displayed a marked increase in Bach2 mRNA expression, compared to that of the other tumor samples and normal spleen (Figure 2B). The discrepancy between the results obtained for the different primer combinations for this particular tumor sample led us to proceed with other primer combinations. Also for primer combinations spanning Bach2 exons 4 to 5 (Figure 2C) and exons 3 to 4 (Figure 2D) an up-regulation of Bach2 expression in tumor 1206 was evident as compared to the other tumor samples. Thus, in tumor 1206, a preferential up-regulation of Bach2 transcripts including exon sequences spanning exon 3 to exon 8 was observed. Western blot analyses were carried out with a polyclonal antibody identifying the N-terminus of the Bach2 protein encoded by exon 4 . We detected an even expression level of a 110-KDa protein, corresponding to the expected size of Bach 2 protein [1], in tumors from mouse 1206 and other tumors (data not shown).

\section{Identification of an alternative Bach2 promoter}

The observation of an increased Bach 2 mRNA expression level specifically for exon sequences located downstream 
A

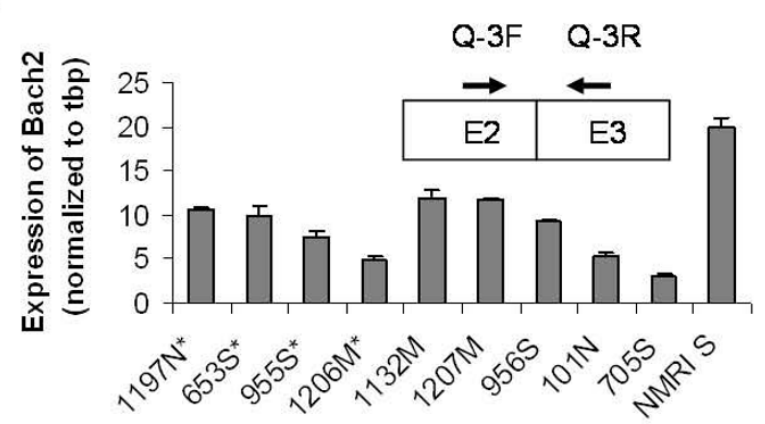

C

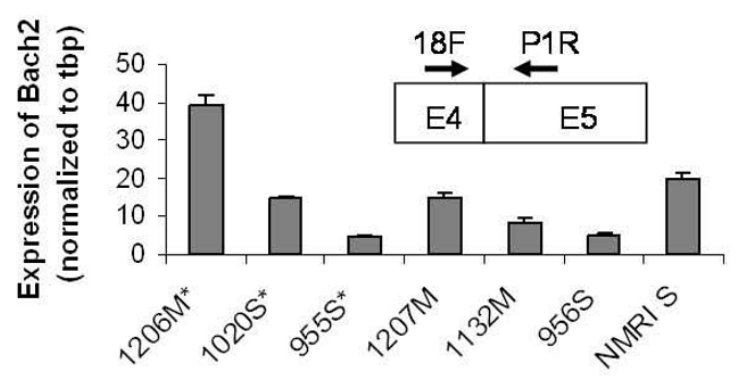

$\mathrm{E}$

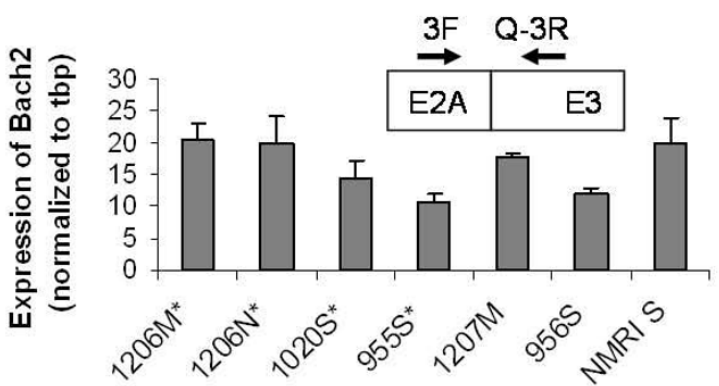

B

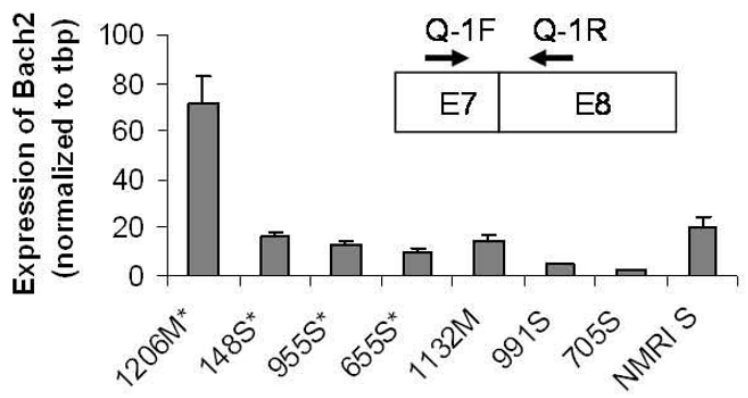

D

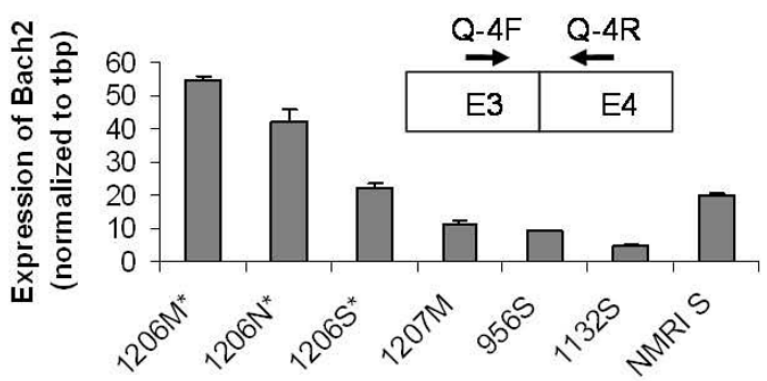

Figure 2

Expression analysis screened out a Bach2 integration site with high mRNA expression level. Q-PCR was performed on total RNAs from tumors with (asterisked) or without proviral integration in Bach2. The used primer pairs and their schematic localization is shown in (A), (B), (C), (D), and (E) (for localization and origin of exon 2A, see figure 5 and text). M, N, and $S$ (mesenteric, cervical (neck) lymph node, and spleen, respectively) refer to types of tumor tissues used for the analyses. Bach2 expression levels were normalized to the tbp expression level and the Bach2 expression level in spleen tissue from untreated NMRI mice (NMRI S) was given the value 20.

of exon 2 in tumors from mouse 1206 let us hypothesize that this was due to activation of alternative promoter sequences present within intron 2 of the Bach 2 gene. Such promoter sequences would result in the generation of a novel first exon if appropriate splice donor sequences were present or alternatively in a continuous 5 '-extension to exon 3 . It should be noted that the transcriptional orientation of the provirus in tumor 1206 was opposite to that of Bach2, thus minimizing the possibility that the virus directly contributed such an alternative promoter.

In a first attempt to address the nature of a possible alternative Bach2 promoter we searched for indicative ESTs. One spliced EST sequence, AK042574, was identified which could have origin in the usage of a Bach 2 intron 2 located promoter. By RT-PCR analysis we verified the existence of the RNA corresponding to the EST (data not shown). The first exon of the EST was denoted exon 2A. By usage of different primer combinations in various RT-PCR analyses, splicing from exon $2 \mathrm{~A}$ to exon 3 was identified. However, no up-regulation of this transcript was observed in material from tumor 1206 compared to other tumors and normal spleen (Figure 2E). Thus, the promoter sequence in front of exon $2 \mathrm{~A}$ seems not to be the target for the observed Bach2 deregulation in tumor 1206.

In a further search for alternative promoter sequences within intron 2 , the possibility of a continuous 5 '-exten- 
sion of exon 3 was examined. By RT-PCR analysis using mesenteric lymphoma RNA from mouse 1206 we could by the use of a reverse primer located within exon 4 and a forward primer located immediately upstream of exon 3 (primer 2F) (see Figure 3A for primer localizations) detect a band corresponding to a transcript including Bach2 intron 2 sequences as a novel exon (Figure $3 \mathrm{~B}$, left). This was further substantiated by using a forward primer, $10 \mathrm{~F}$, located 667 bp upstream of exon 3 which also resulted in a PCR product corresponding to a Bach2 mRNA species including intron 2 sequences (Figure 3B, right).

In order to determine the 5 ' end of this novel mRNA subtype, we performed 5' RACE analysis on the mesenteric lymphoma RNA from mouse 1206 using either reverse primer $1 e$ or $1 \mathrm{f}$ located upstream from exon 3 (see Figure 3A). Two distinct 5' ends of mRNAs were identified, located $1185 \mathrm{bp}$ and $1163 \mathrm{bp}$ upstream of exon 3, respectively (Figure 3C). We have found no evidence of the exist-
A

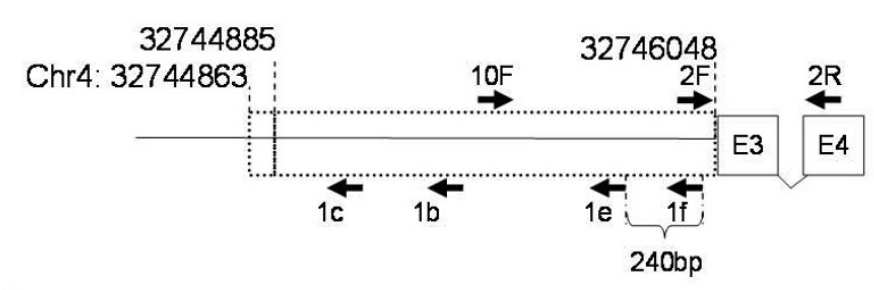

D

\begin{abstract}
ttaaataattttttagagaacaaaagaaga accgtggttctgcatccaaagtacccaggt tcagttcccagcacctacttggaggctcc aactgtctataactccagtctcaggggatc tgacaccatcttttggcttacgcaggcact atatacaggagggctgcatgcacatggtgo attgttatacattcaagcaaacactcatac $\longmapsto$

ACATAAAGTAAAAATATATAAAATCTCAAA AAAAAAACCCTAAAGAAAAACTTGTGAGGA CATGCT -32744928
\end{abstract}

E

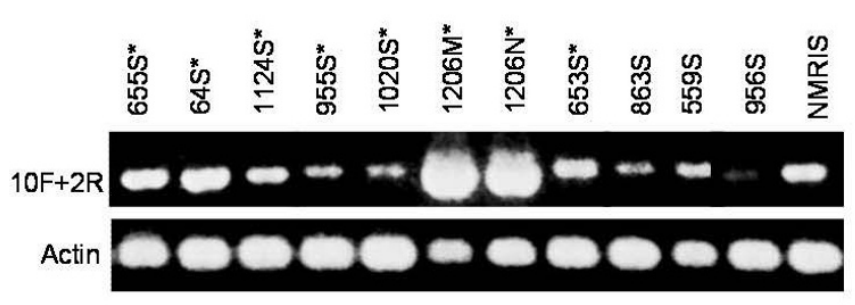

B
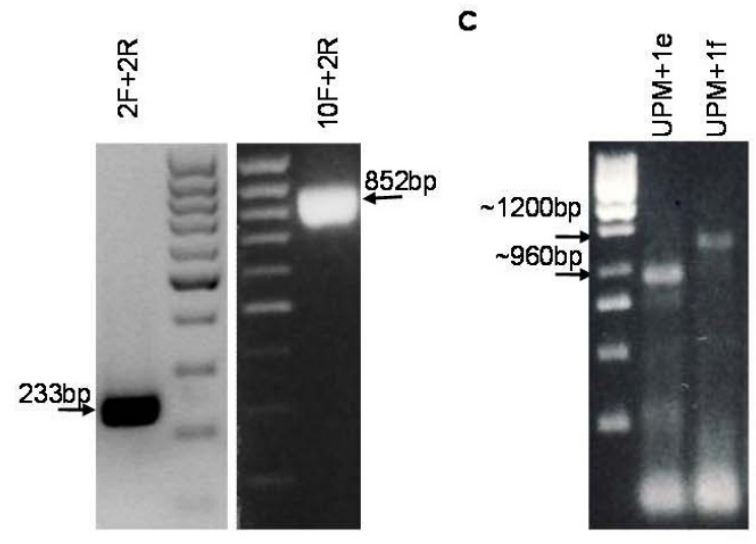

F

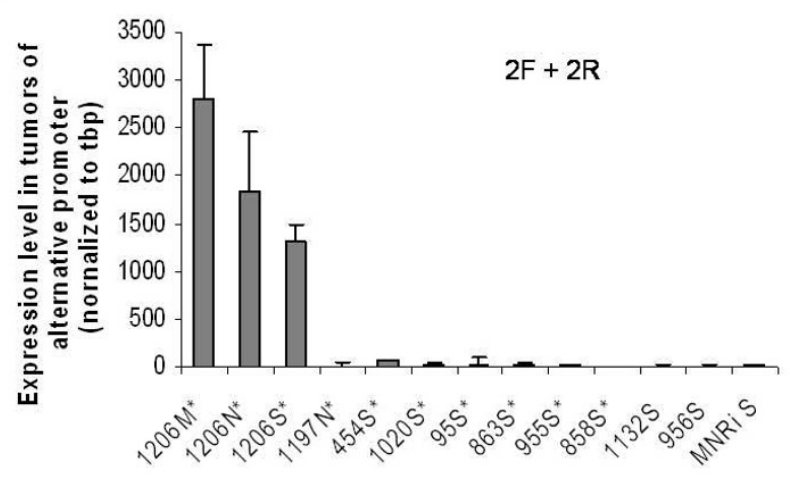

\section{Figure 3}

Identification and characterization of an alternative Bach2 promoter. (A) Map of the $5^{\prime}$ ends for the novel mRNAs determined by 5'RACE and primers employed in 5' RACE PCR and sequencing (Ic, Ib, le, If), and in RT-PCR and Q-PCR (IOF and $2 R$ and/or $2 F$ and $2 R$ ). Chromosomal locations refer to UCSC version 2006 February. (B) RT-PCR detection of transcripts including intron 2 sequences as a novel Bach2 exon. Tumor material from mouse I 206 was analyzed by RT-PCR using primers $2 \mathrm{~F}$ and $2 \mathrm{R}$ (left panel) or IOF and 2R (right panel) and by ethdium bromide staining. (C) 5'-RACE analysis to detect novel Bach2 promoters. The products of the RACE PCR analysis were visualized by ethdium bromide staining. Arrows indicate the product bands. (D) Sequence around the alternative promoter. Exon sequences are in capital letters and position of mapped transcriptional start sites indicated by arrows. (E) RT-expression analysis of transcripts derived from the alternative Bach2 promoter. Tumor material with (marked by asterisk) or without Bach2 gene proviral integration were analyzed by RT-PCR with primers $\mathrm{IOF}$ and $2 \mathrm{R}$ and the products visualized by ethdium bromide staining. (F) Q-PCR analyses of transcripts with origin from the alternative Bach2 promoter. Analyses were done using primers $2 \mathrm{~F}$ and $2 \mathrm{R}$ on tumors with (asterisked) or without proviral integration in Bach2 and spleen tissues from untreated NMRI mice (NMRI S). Expression levels were normalized to tbp and NMRI $\mathrm{S}$ with the expression level for NMRI S set to 20 . 
ence of splice donor sequences in the region between the alternative promoter sequences and exon 3, suggesting that the resulting transcripts indeed included a continuous 5 '-extension to exon 3 . The corresponding novel alternative first Bach2 exon was denoted E3L. No consensus TATA-box was present within the proximal promoter sequence. As translation of Bach2 initiates in exon 4, inclusion of E3L does not affect the Bach2 coding region. Moreover, no additional open reading frames were detected within the E3L sequences.

To examine if the alternative Bach2 promoter was active only in tumor 1206 material, we screened RNA from several tumors for the presence of such an alternative Bach2 transcript. By RT-PCR using forward primer $10 \mathrm{~F}$ in combination with primer $2 \mathrm{R}$ we identified a $852 \mathrm{bp}$ band in all examined tumors and in normal spleen corresponding to the Bach 2 transcript including exon E3L (Figure 3E). Thus, the alternative promoter appears active both in tumor tissue and in normal spleen. Albeit semi-quantitative, the assay also pointed at an up-regulation of alternative Bach2 promoter in tumor 1206 as compared to the other examined tissue samples.

To further analyze the expression level from the alternative Bach2 promoter, Q-PCR assay was done using primers $2 \mathrm{~F}$ and $2 \mathrm{R}$ (Figure 3F). This assay showed a 134-fold higher expression level of the Bach2 transcript resulting from the alternative promoter within mesenteric lymphoma from mouse 1206, when compared to the average expression level in the other examined tumors and in normal spleen (Figure 3F). Thus, the alternative Bach 2 promoter was highly activated in tumor 1206 . The amount of Bach2 transcripts derived from the alternative promoter was similar in all types of tumor tissues examined from mouse 1206 (Figure 3F).

\section{Activity comparison between the alternative and normal Bach2 promoters}

To examine the relative amount of Bach2 transcripts derived from the alternative promoter compared to the normal promoter we used a Q-PCR based assay. cDNA representing the Bach2 transcript derived from the normal promoter was amplified using primer pairs in exon 1 (primer P1F) and exon 3 (primer Q3R) and cDNA representing the Bach 2 transcript from the alternative promoter was amplified using a primer located in exon 3L immediately upstream of the beginning of exon 3 (primer $2 \mathrm{~F}$ ) and an exon 4 primer (primer 2R). The amplification efficiency for the two Bach 2 amplicons was determined to be equivalent $(\sim 95 \%)$ as estimated from Q-PCR reactions performed on serial dilutions on purified cDNA representing the two Bach2 transcripts (data not shown). QPCR analyses were performed on CDNA from tumor 1206 and from normal spleen and both random primed and oligo dT primed cDNA was examined to account for bias in cDNA synthesis reactions (Figure 4). In cDNA synthesised from tumor 1206 mRNA the amount of the two types of Bach 2 cDNA was comparable (Figure 4). This similarity in expression levels was observed both in randomprimed and oligo dT primed cDNA (Figure 4A and 4B). In normal spleen the level of the Bach 2 cDNA derived from the normal promoter was comparable with the cDNA level in tumor 1206 whereas the amount of the alternative promoter derived Bach 2 cDNA was present in a low amount (Figure 4).

We next examined the tissue specificity of the alternative Bach2 promoter relative to that of the normal promoter. RNA representing ten types of organs from mice not infected with retrovirus was examined by Q-PCR using primer pairs amplifying sequences representing the two Bach2 transcripts as described above. As seen in Figure 5, transcripts originating from both the alternative and the normal promoters were more abundant in hematopoietic tissues, for example thymus, spleen, and bone marrow, compared with that in other tissues such as kidney, heart, lung, or skeleton muscles. Interestingly, in brain and testis, the alternative promoter tends to be utilized relatively more than the normal promoter as compared to the hematopoietic tissues (Figure 5). We note that in none of the examined tissues the alternative Bach 2 promoter seemed to be the major source of Bach2 transcripts.

\section{Alternative usage of Bach2 terminal exons}

The identification of the alternative Bach 2 mRNA isoforms described above points to a transcriptional complexity of the Bach 2 locus. To address this further we by in silico analysis searched for EST sequences representing other alternative Bach 2 exons. Several such putative exons were identified and illustrated in Figure 5. The ESTs BC099420 and AK162095 are indicative of the presence of two novel alternative Bach2 exons spliced to the exon 4. These two exons are denoted exon 5A and exon 5B. Exon $5 \mathrm{~A}$ (second exon in BC099420, the first being exon 4) contains a consensus poly-A signal, and the corresponding EST sequence includes a poly-A tail. Thus, the inclusion of exon 5A in the Bach 2 transcript appears to generate a transcript in which exon 5 to exon 8 are skipped. The existence of Bach2 mRNAs containing exon 5A was verified by RT-PCR and sequencing of tumor material from mouse 1206 (data not shown). Also the existence of a spliced transcript including exon 3 , exon 4 , and exon $5 \mathrm{~A}$ was identified in tumor 1206 material (data not shown). We have not been able to detect Bach2 mRNA containing exon 5A in any tumor samples except 1206, or in normal spleen tissue (data not shown). A stop codon is present in exon $5 \mathrm{~A}$ in frame with the Bach2 start codon located in exon 4. 


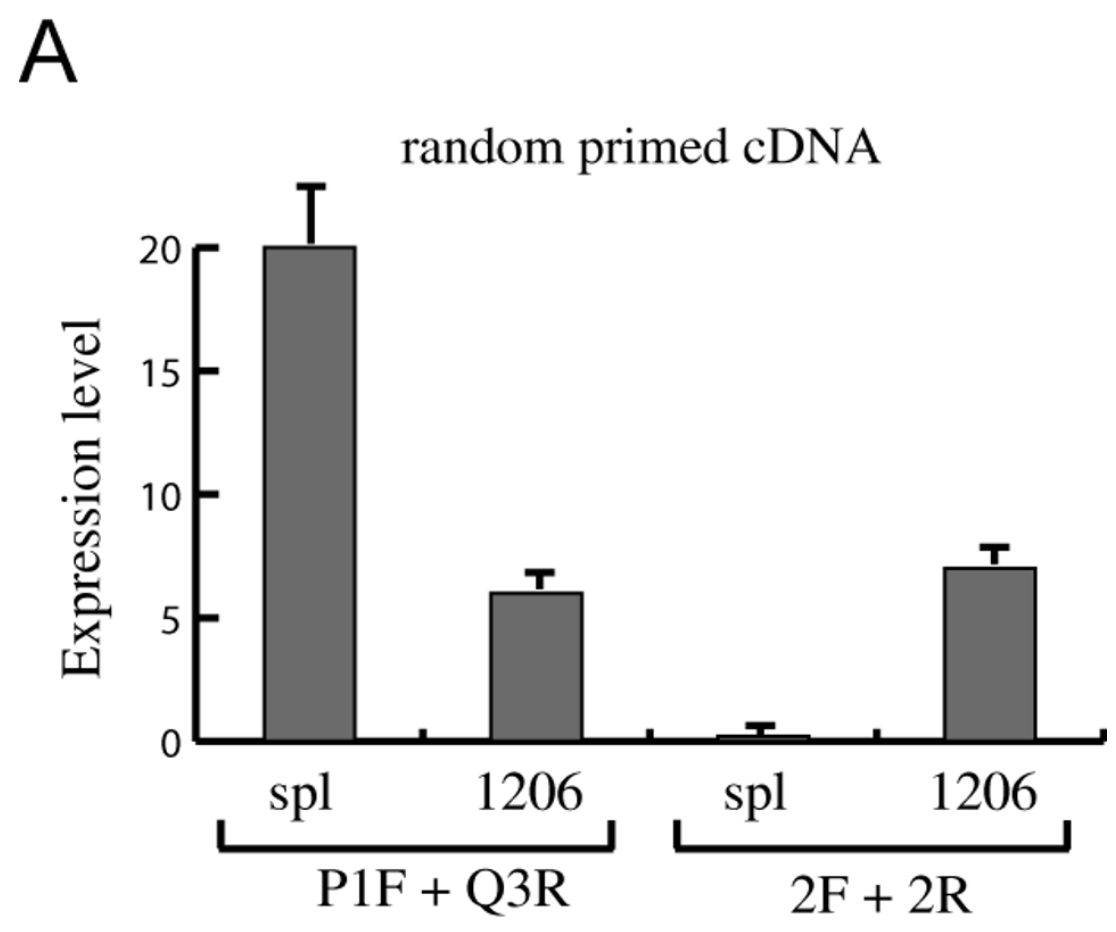

B

oligo dT primed cDNA

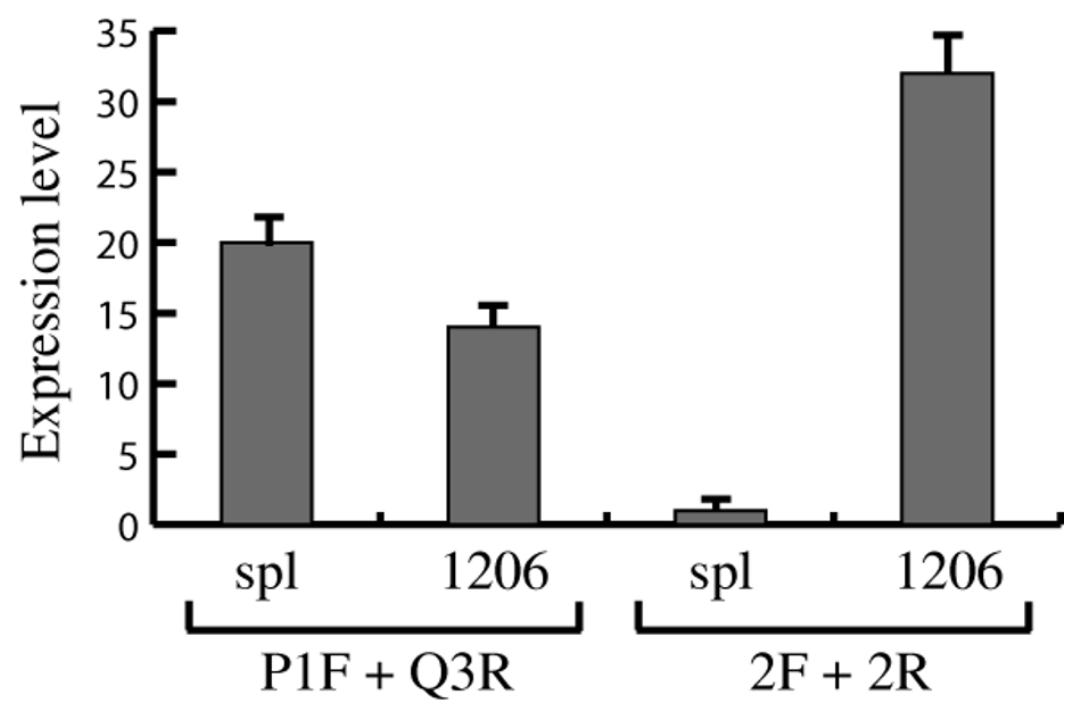

Figure 4

Expression level analysis of Bach2 mRNA derived from the normal or alternative promoter. Quantitative RT-PCR analyses were performed with primer pairs amplifying either cDNA representing transcripts derived from the normal Bach2 promoter (primers PIF and Q3R) or cDNA representing transcripts derived from the alternative promoter (primers $2 \mathrm{~F}$ and 2R). RNA was extracted from NMRI mice spleen (Spl) or tumor 1206 material and cDNA generated using either randomprimed first strand synthesis (panel A) or oligo dT primed first strand synthesis (panel B). Expression levels were normalized to the tbp expression level and the expression levels for the normal Bach2 transcript in NMRI spl set to 20. 
A

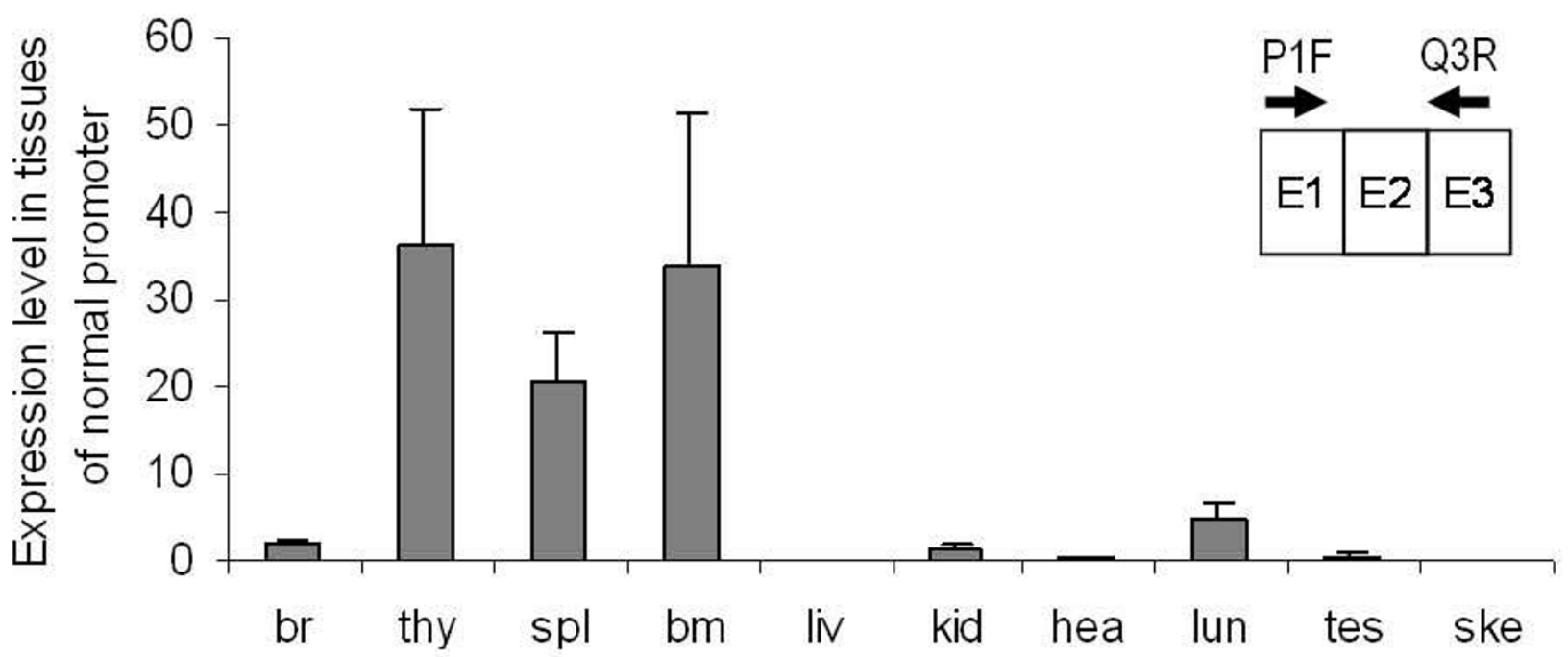

B

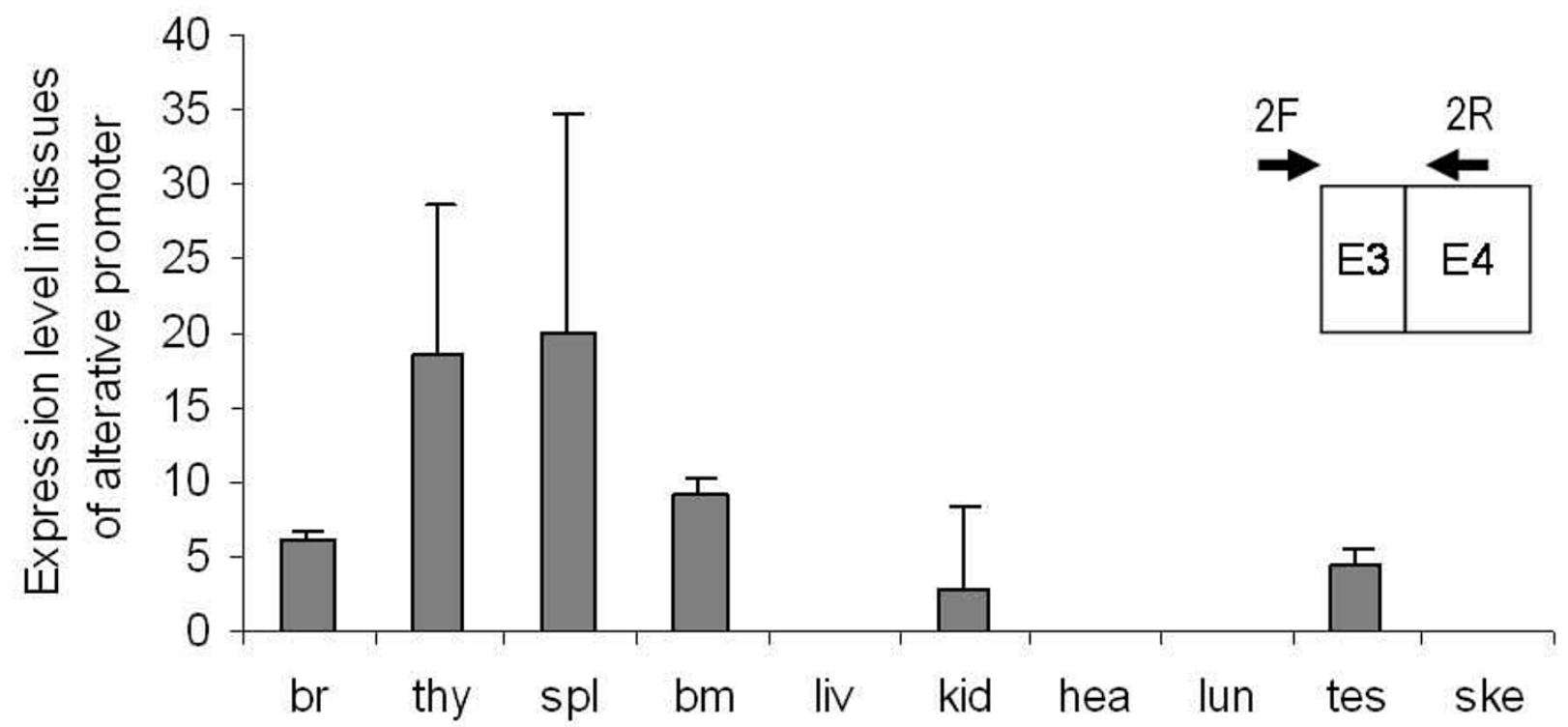

Figure 5

Expression in mouse tissues of Bach2 mRNA derived from the normal or alternative promoter. Q-PCR analyses were performed with primer pairs amplifying either transcripts derived specifically from the normal Bach2 promoter (panel A) or transcripts derived from the alternative promoter (panel B). cDNAs used for the assay were obtained from NMRI mice not infected with retrovirus. br, brain; thy, thymus; spl, spleen; bm, bone marrow; liv, liver; kid, kidney; hea, heart; lun, lung; tes, testis; ske, skeletal muscle. Expression levels were normalized to total RNA and spleen tissue; expression level for spleen by normal promoter was set to 20 . 
The existence of Bach 2 mRNAs including exon 5B (the second exon of EST AK162095) was verified by RT-PCR and sequencing of tumor material from mouse 1206 (data not shown). Again, we were not able to detect mRNA containing exon $5 \mathrm{~B}$ in other tumor samples than tumor 1206 , or in normal spleen tissue (data not shown). The 3'-end of the exon 5B sequence derived from EST AK162095 includes no poly-A signal, and therefore might be protruded to the polyadenylation signal located for exon 4A. We note a distance of $15 \mathrm{~kb}$ between the poly-A site of exon $5 \mathrm{~A}$ and the 3 '-end of the EST sequence of exon $5 \mathrm{~B}$, and accordingly we have not been able to determine if exon $5 \mathrm{~B}$ indeed is extended to the same polyadenylation signal as exon 5A (data not shown). We also note that we have been unable to detect splicing between exon $5 \mathrm{~B}$ and downstream Bach2 exons by RT-PCR. A stop codon is present in exon $5 \mathrm{~B}$ in frame with the Bach2 start codon located in exon 4. According to the rules of non-sense mediated decay splicing of exon 5B to exon 5 will generate a substrate for degradation supporting that exon $5 \mathrm{~B}$ in itself contains a polyadenylation signal.

From the RT-PCR analyses, it was evident that still another alternative exon sequence exists. This exon, denoted exon $4 \mathrm{~L}$, results from the absence of splicing between exon 4 and exon $5 \mathrm{~B}$ and accordingly have a termination similar to exon $5 \mathrm{~B}$ (data not shown). Bach2 transcripts including this exon $4 \mathrm{~L}$ was detected in tumor 1206 material as well as in other tumor samples, and also in normal mouse spleen (data not shown). Splicing between exons $3 \mathrm{~L}$ and $4 \mathrm{~L}$, as well as between exons 1, 2, 3, and $4 \mathrm{~L}$ was detected by RT-PCR, and thus both the normal and the here identified alternative Bach2 promoter may generate Bach2 transcripts including exon $4 \mathrm{~L}$.

\section{Inclusion of alternative Bach2 terminal exons results in generation of novel Bach2 protein isoforms}

The inclusion of exon $5 \mathrm{~A}, 5 \mathrm{~B}$, or $4 \mathrm{~L}$ in the Bach2 transcript results in the generation of C-terminally truncated Bach2 ORFs, which lack the b-ZIP DNA binding domain. The coding regions in common share the $\mathrm{N}$-terminal part of the Bach2 BTB domain encoded by exon 4 . This segment constitutes the major part of the BTB domain (see Figures 1 and 6). Inclusion of exon 5A or exon $5 \mathrm{~B}$ in the Bach2 transcript results in the generation of 132 and 82 amino acids Bach2 ORFs, respectively, in which the first 81 amino acids are identical. Inclusion of exon $4 \mathrm{~L}$ results in the generation of a 83 amino acids ORF in which the first 81 amino acids are identical to the Bach2 isoform encoded from exon 5B (Figure 7A).

The canonical Bach2 protein is localized in the cytoplasm by its C-terminal cytoplasmic localization signal and nuclear-export signal [7]. To determine the localization of the alternative Bach 2 protein isoforms, we cloned the
ORFs of the 132 and 83 amino acid variants in the mammalian pSG5FLAG expression vector, which accordingly was used to express the Bach2 proteins in NIH 3T3 cells or HEK 293 T cells as FLAG tagged fusion proteins. Immunofluorescence analysis showed that both proteins were nuclear-excluded (Figure 7B). Instead a peri-nuclear localization was observed (Figure 7B). No difference in the localization of the 132 amino acid and 83 amino acid Bach 2 protein isoforms was evident. Thus, the addition of the C-terminal extension in the 132 aa Bach2 isoform had no clear consequence on localization. The integrity of the expressed Bach2 proteins was confirmed by Western blotting (Figure 7C). In conclusion, transcription from the Bach2 locus directs expression of alternative protein isoforms with the same subcellular localization but different composition of functional domains.

\section{Discussion}

We here report proviral integration into the Bach2 gene in 18 independent B-cell lineage tumors induced by Akv or Akv derived MLV in NMRI mice. Proviral integration was identified and confirmed by PCR analysis and sequencing. All cases of proviral insertion were located in intron sequences upstream of the translational start codon of the canonical Bach2 mRNA or within the Bach2 promoter region and most of the integrations were in the opposite transcriptional orientation to that of the Bach2 gene. Thus, our analyses support previous findings of Bach2 locus being a common integration site (CIS). Fourteen Bach2 integrations are reported in the Retrovirus Tagged Cancer Gene Database (RTCGD) [32,33], thirteen of which originate from Akv induced malignancies in mouse strains of AKxD and NFS [34,35]. The distribution pattern of these 13 integrations shows remarkable similarity to what we have demonstrated in the present study: they all are B-cellrelated, located in non-coding sequences from the promoter region to intron 3 , and predominantly having an inverse orientation. The frequency of targeting specific genes depends on both the mouse host strain and the type of retrovirus. In one mouse strain different types of malignancy can be induced by different retroviruses. For example, in NMRI mice Akv and SL3-3 MLVs induce B- and Tcell lymphomas, respectively [36-38]. The same retrovirus may also behave diversely in various host strains. For example, the Icsbp gene is an Akv-related target in NMRI mice, but not in other mouse strains such as AKR, AKxD, and NFS [39-42]. Bach2 seems to be a target gene in a variety of host genetic backgrounds for Akv induced B-cell malignancies. Besides the thirteen Akv MLV integration sites, RTCGD contains one Moloney MLV integration site within in the Bach 2 gene, which is derived from a brain tumor in the mutated C57BL/6 (Ink4a/Arf (-/-)) strain [43]. This integration site is located at intron 4 , and accordingly disrupting the coding sequences. Notably, in humans, BACH2 was also identified to be recurrently inte- 


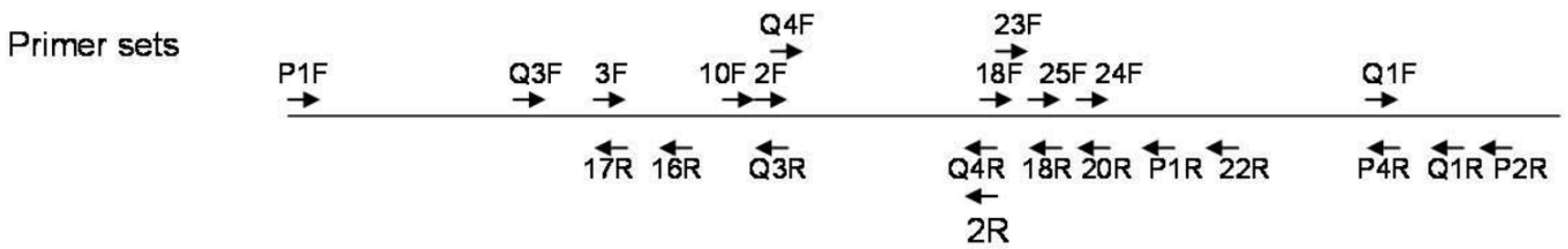

NM 007521
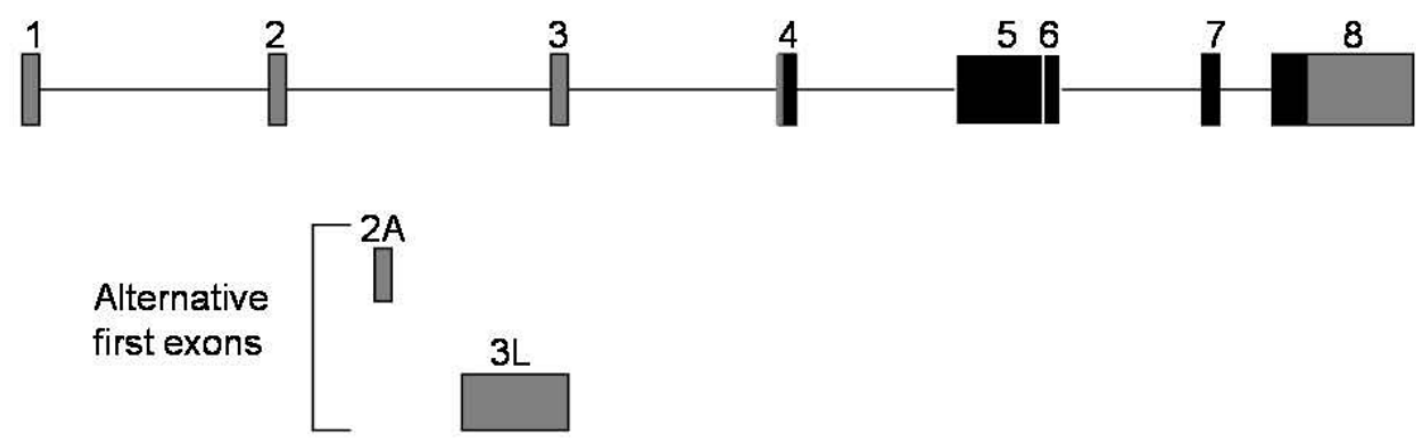

\section{Figure 6}

Genomic structure for Bach2 gene with positioning of alternative exon sequences. Top panel depicts primer sets used in the identification of Bach2 mRNA isoforms. Coding sequences were shown in dark boxes and non-coding sequences in grey. For exon $5 B$ and $4 \mathrm{~L}$ the 3 '-end of the exon was not mapped and the possible extension to the polyadenylation signal present in exon $5 \mathrm{~A}$ was indicated by a dashed box.

grated by HIV in human CD4+ T cells [44]. These integrations were all in intron 5 and had all same transcriptional orientation as the $\mathrm{BACH} 2$ gene.

By Southern blot analysis using an ecotropic envelope probe and Bach2 gene specific probes, we analyzed clonality of the B-lymphomagenic tumors induced by Akv and Akv derived MLV in inbred NMRI mice. By this approach we have not been able to detect the virus integration within the tumor in accordance with only a small fraction of the tumor cells having the actual integration. Such a Southern blot pattern resembles what we have described in a previous report for Akv MLV derivates in the NMRI mouse strain [23,41]. A model for this observation could be that B-cell lymphoma induction by Akv MLV in the inbred NMRI mouse strain may involve immune stimulation [24]. Such stimulation may cause an initial polyclo- nal stimulation followed by multiple events of mutagenesis by proviral insertion. Given that only a minor fraction of the tumor cells harbours the proviral integration, it may not be surprising that in most cases we were unable to detect Bach2 transcriptional deregulation. Still, in tumors from mouse 1206 transcriptional upregulation of Bach2 was detected. This upregulation was however only observed for exon 3 to exon 8 sequences, and accordingly pointed to activation of an alternative Bach2 promoter located in intron 2. Indeed, we were able to identify such a novel Bach 2 promoter and in accordance with the expression data we observed increased expression within tumor material from mouse 1206. Moreover, we found that in tumor 1206 material the expression level of the Bach 2 transcript derived from the alternative promoter was similar to the expression level the Bach2 transcript driven from the normal promoter. 
A

\begin{tabular}{ll} 
Exon 4+ & MSVDEKPGS PMYVYES TVHCANILL \\
exon 5A & GRAVQRKKDILCDVTLIVERKEFRA \\
(132 aa) & VSLPEEIYLHRLTPGLSGCVKDISNS \\
& CCLEDVSVETGIISQMAFQKRSHSH \\
\hline PSLCFIQ
\end{tabular}

Exon 4+ MSVDEKP GSPMYVYESTVHCANILI exon 5B GLNDQRKKDILCDVTLIVERKEFRA

Exon 4L MSVDEKPGSPMYVYESTVHCANILI (83 aa) GLNDQRKKDILCDVTLIVERKEFRA HRAVLAACSEYEWQALVGQTKDDLV VSLPEEVQ

c

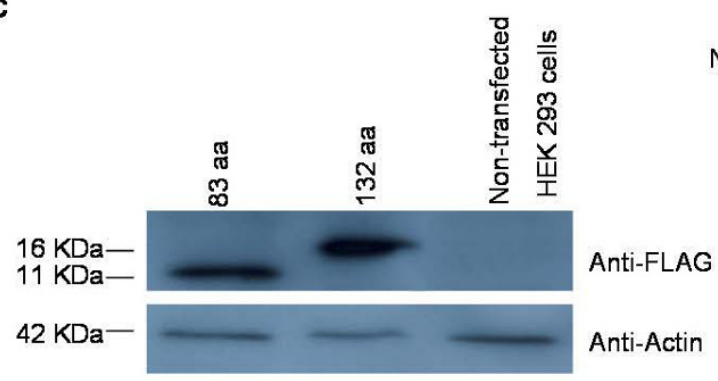

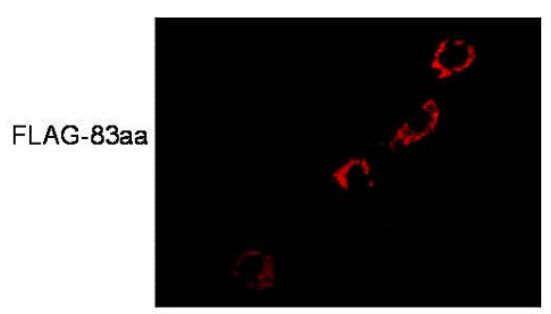
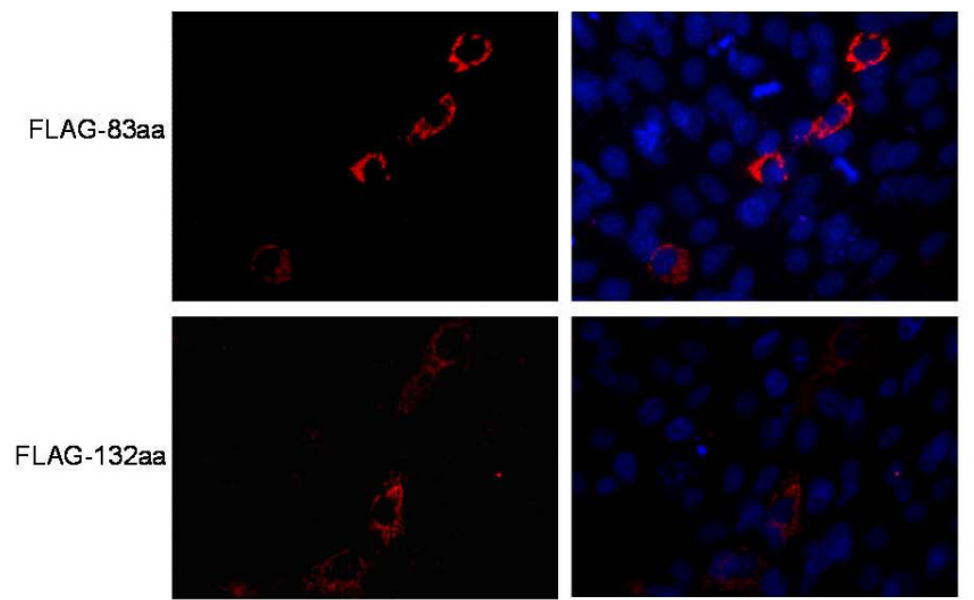

Non-transfected $\mathrm{NIH} 3 \mathrm{~T} 3$ cells

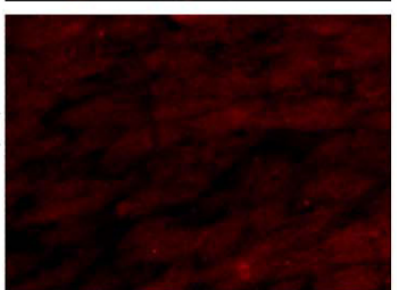

FLAG-staining

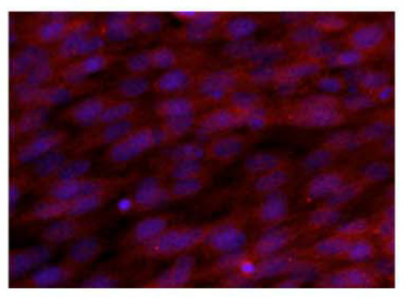

Overlay of FLAG-staining \& DAPI-staining

\section{Figure 7}

Identification of novel Bach2 protein isoforms. (A) Amino acid sequence of the Bach2 protein isoforms resulting from translation of Bach2 mRNA including exon 5A, 5B, or $4 \mathrm{~L}$. BTB domain sequences are underlined and the sequences different from the canonical BTB domain are in bold letters. (B) Sub-cellular localization of the Bach2 I 32 aa (encoded by exon 5A including transcript) and 83 aa (encoded by exon $4 \mathrm{~L}$ including transcript) isoforms. NIH-3T3 cells were transfected with expression vectors encoding N-terminal FLAG-tagged open reading frames of the Bach2 isoforms. 48 hours after transfection cells were immunostained with anti-FLAG antibody and a TRITC-conjugated secondary antibody. Fluorescence was monitored by epi-fluorescence microscopy. DAPI staining was used to localize the nuclei. Non-transfected NIH3T3 cells served as negative control. (C) Western blot analysis of the Bach2 proteins. HEK-293 cells were transfected with the FLAG-tagged Bach2 expression constructs described in (B) and cellular extracts analyzed by western blotting using an anti-FLAG antibody. Molecular weight markers are indicated to the left.

Interestingly, the alternative Bach2 promoter was also identified to be active in normal mouse tissues and accordingly could play a role in the normal regulation of Bach2 expression. The tissue specificity of the two Bach2 promoters was overlapping, but we note that the alternative promoter in some non-hematopoietic tissues had an increased relative expression indicating that the contribution to the overall Bach2 mRNA level could be of physiological importance in such tissues. We did not observe normal tissues in which the alternative promoter derived Bach2 transcript was expressed at a higher level than the normal Bach2 transcript, but the results point out that transcription directed from this alternative Bach2 pro- moter is important to include in future expression analysis addressing Bach2. Usage of the intron 2 promoter will if the transcript is spliced from exon 3 L to exons 4, 5, 6, 7 and 8 result in generation of the normal Bach 2 protein, as the start codon is located in exon 4 . The identification of proviral integrations also in the normal promoter region of Bach 2 and in intron 1 supports that upregulation of the canonical Bach2 protein is involved in MLV-induced tumorgenesis.

Our RT-PCR analysis showed that besides the usage of alternative promoter sequences Bach2 gene regulation also involves alternative usage of terminal exons. Such ter- 
minal exons were identified in intron 4 of the Bach2 gene. The inclusion of alternative terminal exons resulted in the skipping of exons 5 to 8 from the Bach2 transcript. Transcripts arising from both the normal Bach2 promoter and from the novel Bach2 promoter were identified to include such alternative terminal exons and the resulting transcripts have coding potential for novel subtypes of Bach2 protein having C-terminal truncations and inclusion of new amino acid compositions. The canonical Bach2 protein consists of both a BTB domain at the $\mathrm{N}$-terminus and a bZip domain near the C-terminus. All of the deduced proteins for these isoforms possess a fragment of the BTB domain but lack the bZip domain. The BTB domain, also known as the POZ (poxvirus zinc finger) domain, was originally identified as a conserved motif in the Drosophila proteins bric à brac, tramtrack and Broad-Complex $[45,46]$. The BTB domain is involved in a variety of cellular functions, including transcription repression [47], cytoskeleton regulation $[48,49]$, and targeting protein for ubiquitination/degradation [50-53]. The BTB domains from the BTB-bZip proteins (Bach1 and Bach2) are of an elongated form (around 120 residues in total), containing an additional amino-terminal region to the highly conserved BTB core region which consists of 95 residues [54]. As protein-protein interaction domains, the BTB domains are involved in forming homo- and hetero-dimerization, as well as protein oligomerization, with a specificity depending on their amino-acid sequences and structure (reviewed in [3]). Note the BTB domain was shown not to be required for the interaction between Bach2 and B-cell lymphoma 6 (BCL6) proteins in vitro [55]. Although the BTB sequences included in the hereby identified novel short Bach2 protein isoforms are truncated compared to the BTB domain in normal Bach2, they share the aminoterminal region which was predicted to confer stable dimerization [54]. We propose that these alternative proteins may play roles distinct to normal Bach2 either independently or by forming competitive protein interactions in for example the B-cell compartment with normal Bach2 protein. The involvement of such small Bach2 proteins in tumorgenesis is also an interesting possibility as they could have a dominant negative effect on normal Bach2 functions through formation of protein-protein interactions but generating protein complexes that lack the DNA binding domain normally contributed by Bach2. In light of the fact that Bach2 is not expressed in the plasma cell stage, Bach2 proteins most probably play their part in upstream steps of the tumorgenesis. Functional analyses of alternative Bach2 transcripts and proteins are in progress to further elucidate this issue and clarify the importance for normal cellular regulation as well as B-cell lymphomagenesis.

\section{Conclusion}

The common insertion of proviruses at the Bach2 locus in a murine model of B-lymphomagenesis provides strong evidence that mutation at this locus plays a role in the disease. In this work we have identified an alternative promoter and new protein isoforms of Bach2 and our data imply that activation of an alternative promoter by proviral integration serves as a possible mechanism of up-regulation of the Bach2 gene with a potential role in B-cell lymphomagenesis. Such differential expression of protein isoforms with distinct functions may explain why the Bach2 gene, previously suggested to be a tumor suppressor may be up-regulated in B-cell lymphomas. The finding of novel Bach2 transcripts and protein isoforms will facilitate a better insight into the normal and pathophysiological regulation of the Bach2 gene.

\section{Authors' contributions}

JL carried out all experimental work except large scale screening for proviral insertion sites and the data presented in Figure 4 and wrote the first manuscript draft. BW and MW performed the large scale screening for proviral insertion sites. ALN performed the Q-PCR analysis presented in Figure 4. ABS, ALN, and FSP conceived of the study and contributed to the design and interpretation of experiments as well as to editing of the manuscript.

\section{Acknowledgements}

This project was supported by grants from The Danish Cancer Society (ALN, FSP), The Danish Research and Innovation Agency (ALN, FSP), and by NIH grant ROICAI 00266 (M.W). ALN is supported by a Hallas-Moller fellowship from the NovoNordisk Foundation.

\section{References}

I. Oyake T, Itoh K, Motohashi H, Hayashi N, Hoshino H, Nishizawa M, Yamamoto $M$, Igarashi $\mathrm{K}$ : Bach proteins belong to a novel family of BTB-basic leucine zipper transcription factors that interact with MafK and regulate transcription through the NF-E2 site. Mol Cell Biol I 996, I 6( I I ):6083-6095.

2. Albagli O, Dhordain P, Deweindt C, Lecocq G, Leprince D: The BTB/POZ domain: a new protein-protein interaction motif common to DNA- and actin-binding proteins. Cell Growth Differ 1995, 6(9): I I93-II98.

3. Perez-Torrado R, Yamada D, Defossez PA: Born to bind: the BTB protein-protein interaction domain. Bioessays 2006, 28(I 2): I | 94-I 202.

4. Vinson C, Acharya A, Taparowsky EJ: Deciphering B-ZIP transcription factor interactions in vitro and in vivo. Biochim Biophys Acta 2006, I759(I-2):4-I2.

5. Hoshino $\mathrm{H}$, Igarashi $\mathrm{K}$ : Expression of the oxidative stress-regulated transcription factor bach 2 in differentiating neuronal cells. J Biochem 2002, I32(3):427-43I.

6. Muto A, Hoshino $\mathrm{H}$, Madisen L, Yanai N, Obinata M, Karasuyama $\mathrm{H}$, Hayashi N, Nakauchi H, Yamamoto M, Groudine M, et al.: Identification of Bach2 as a B-cell-specific partner for small maf proteins that negatively regulate the immunoglobulin heavy chain gene 3' enhancer. EMBO J 1998, I 7(19):5734-5743.

7. Hoshino H, Kobayashi A, Yoshida M, Kudo N, Oyake T, Motohashi $\mathrm{H}$, Hayashi N, Yamamoto M, Igarashi K: Oxidative stress abolishes leptomycin B-sensitive nuclear export of transcription repressor Bach2 that counteracts activation of Maf recognition element. J Biol Chem 2000, 275(20): I5370-I5376.

8. Yoshida C, Yoshida F, Sears DE, Hart SM, lkebe D, Muto A, Basu S, Igarashi K, Melo JV: Bcr-Abl signaling through the PI-3/S6 kinase pathway inhibits nuclear translocation of the transcription factor Bach2, which represses the antiapoptotic factor heme oxygenase- I. Blood 2007, I 09(3): I 2 I I-I 219.

9. Kamio T, Toki T, Kanezaki R, Sasaki S, Tandai S, Terui K, Ikebe D, Igarashi $\mathrm{K}$, Ito E: B-cell-specific transcription factor BACH2 
modifies the cytotoxic effects of anticancer drugs. Blood 2003, 102(9):3317-3322.

10. Kono K, Harano Y, Hoshino H, Kobayashi M, Bazett-Jones DP, Muto $A$, Igarashi $K$, Tashiro S: The mobility of Bach2 nuclear foci is regulated by SUMO-I modification. Exp Cell Res 2008, 3 I 4(4):903-9|3.

II. Tashiro S, Muto A, Tanimoto K, Tsuchiya H, Suzuki H, Hoshino H, Yoshida M, Walter J, Igarashi K: Repression of PML nuclear bodyassociated transcription by oxidative stress-activated Bach2. Mol Cell Biol 2004, 24(8):3473-3484.

12. Muto A, Tashiro S, Nakajima O, Hoshino H, Takahashi S, Sakoda E, Ikebe $\mathrm{D}$, Yamamoto $\mathrm{M}$, Igarashi K: The transcriptional programme of antibody class switching involves the repressor Bach2. Nature 2004, 429(699 I):566-57I.

13. Sasaki S, Ito E, Toki T, Maekawa T, Kanezaki R, Umenai T, Muto A, Nagai H, Kinoshita T, Yamamoto M, et al.: Cloning and expression of human B cell-specific transcription factor BACH2 mapped to chromosome 6q I5. Oncogene 2000, 19(33):3739-3749.

14. Sakane-Ishikawa E, Nakatsuka S, Tomita Y, Fujita S, Nakamichi I, Takakuwa T, Sugiyama H, Fukuhara S, Hino M, Kanamaru A, et al.: Prognostic significance of BACH2 expression in diffuse large B-cell lymphoma: a study of the Osaka Lymphoma Study Group. I Clin Oncol 2005, 23(31):8012-80I7.

15. Takakuwa T, Luo WJ, Ham MF, Sakane-Ishikawa F, Wada N, Aozasa $\mathrm{K}$ : Integration of Epstein-Barr virus into chromosome 6q I5 of Burkitt lymphoma cell line (Raji) induces loss of BACH2 expression. Am J Pathol 2004, 164(3):967-974.

16. Baik SY, Yun HS, Lee HJ, Lee MH, Jung SE, Kim JW, Jeon JP, Shin YK, Rhee HS, Kimm KC, et al: Identification of stathmin I expression induced by Epstein-Barr virus in human B lymphocytes. Cell Prolif 2007, 40(2):268-28I.

17. van Lohuizen $M$, Verbeek S, Scheijen $B$, Wientjens $E$, Gulden $H$ van der, Berns A: Identification of cooperating oncogenes in $E$ mumyc transgenic mice by provirus tagging. Cell 199|, 65(5):737-752.

18. Berns A, Mikkers H, Krimpenfort P, Allen J, Scheijen B, Jonkers J: Identification and characterization of collaborating oncogenes in compound mutant mice. Cancer Res 1999, 59(7 Suppl): 1773s-1777s.

19. Uren AG, Kool J, Berns A, van Lohuizen M: Retroviral insertional mutagenesis: past, present and future. Oncogene 2005, 24(52):7656-7672.

20. Jonkers J, Berns $A$ : Retroviral insertional mutagenesis as a strategy to identify cancer genes. Biochim Biophys Acta 1996, I 287(I):29-57

21. Mikkers H, Allen J, Berns A: Proviral activation of the tumor suppressor E2a contributes to $\mathrm{T}$ cell lymphomagenesis in EmuMyc transgenic mice. Oncogene 2002, 2 I (43):6559-6566.

22. Lovmand J, Sorensen AB, Schmidt J, Ostergaard M, Luz A, Pedersen FS: B-Cell lymphoma induction by akv murine leukemia viruses harboring one or both copies of the tandem repeat in the U3 enhancer. J Virol 1998, 72(7):5745-5756.

23. Sorensen KD, Kunder S, Quintanilla-Martinez L, Sorensen J, Schmidt J, Pedersen FS: Enhancer mutations of Akv murine leukemia virus inhibit the induction of mature B-cell lymphomas and shift disease specificity towards the more differentiated plasma cell stage. Virology 2007, 362(I): 179-191.

24. Sorensen KD, Sorensen AB, Quintanilla-Martinez L, Kunder S, Schmidt J, Pedersen FS: Distinct roles of enhancer nuclear factor I (NFI) sites in plasmacytoma and osteopetrosis induction by AkvI-99 murine leukemia virus. Virology 2005, 334(2):234-244

25. Lovmand S, Kjeldgaard NO, Jorgensen P, Pedersen FS: Enhancer functions in $\mathrm{U} 3$ of Akv virus: a role for cooperativity of a tandem repeat unit and its flanking DNA sequences. J Virol 1990, 64(7):3185-3191.

26. Schmidt J, Erfle $\mathrm{V}$, Pedersen FS, Rohmer $\mathrm{H}$, Schetters $\mathrm{H}$, Marquart $\mathrm{KH}$, Luz A: Oncogenic retrovirus from spontaneous murine osteomas. I. Isolation and biological characterization. J Gen Virol 1 984, 65(Pt I 2):2237-2248.

27. Mikkers H, Allen J, Knipscheer P, Romeijn L, Hart A, Vink E, Berns A: High-throughput retroviral tagging to identify components of specific signaling pathways in cancer. Nat Genet 2002, 32(I): 153-159.

28. Wang CL, Wang BB, Bartha G, Li L, Channa N, Klinger M, Killeen N, Wabl M: Activation of an oncogenic microRNA cistron by provirus integration. Proc Natl Acad Sci USA 2006, 103(49): 18680-18684.

29. Sorensen $A B$, Duch M, Jorgensen P, Pedersen FS: Amplification and sequence analysis of DNA flanking integrated proviruses by a simple two-step polymerase chain reaction method. J Virol 1993, 67( I 2):7118-7/24.

30. Sorensen $A B$, Duch M, Amtoft HW, Jorgensen P, Pedersen FS: Sequence tags of provirus integration sites in DNAs of tumors induced by the murine retrovirus SL3-3. J Virol 1996, 70(6):4063-4070

31. Wigler M, Sweet R, Sim GK, Wold B, Pellicer A, Lacy E, Maniatis T, Silverstein S, Axel R: Transformation of mammalian cells with genes from procaryotes and eucaryotes. Cell 1979, 16(4):777-785.

32. Akagi K, Suzuki T, Stephens RM, Jenkins NA, Copeland NG: RTCGD: retroviral tagged cancer gene database. Nucleic Acids Res 2004:D523-527.

33. Retrovirus Tagged Cancer Gene Database (RTCGD) [http:/ Irtcgd.abcc.ncifcrf.gov/]

34. Suzuki T, Minehata K, Akagi K, Jenkins NA, Copeland NG: Tumor suppressor gene identification using retroviral insertional mutagenesis in Blm-deficient mice. EMBO J 2006, 25( I 4):3422-343I.

35. Suzuki T, Shen H, Akagi K, Morse HC, Malley JD, Naiman DQ, Jenkins NA, Copeland NG: New genes involved in cancer identified by retroviral tagging. Nat Genet 2002, 32(I): 166-I74.

36. Blyth K, Terry A, Mackay N, Vaillant F, Bell M, Cameron ER, Neil JC, Stewart M: Runx2: a novel oncogenic effector revealed by in vivo complementation and retroviral tagging. Oncogene $200 \mathrm{I}$, 20(3):295-302.

37. Kim R, Trubetskoy A, Suzuki T, Jenkins NA, Copeland NG, Lenz J: Genome-based identification of cancer genes by proviral tagging in mouse retrovirus-induced T-cell lymphomas. J Virol 2003, 77(3):2056-2062.

38. Nielsen AA, Sorensen AB, Schmidt J, Pedersen FS: Analysis of wildtype and mutant SL3-3 murine leukemia virus insertions in the c-myc promoter during lymphomagenesis reveals target site hot spots, virus-dependent patterns, and frequent errorprone gap repair. J Virol 2005, 79(I):67-78.

39. Gilbert DJ, Neumann PE, Taylor BA, Jenkins NA, Copeland NG: Susceptibility of AKXD recombinant inbred mouse strains to lymphomas. J Virol 1993, 67(4):2083-2090.

40. Hartley JW, Chattopadhyay SK, Lander MR, Taddesse-Heath L, Naghashfar Z, Morse HC 3rd, Fredrickson TN: Accelerated appearance of multiple $B$ cell lymphoma types in NFS/N mice congenic for ecotropic murine leukemia viruses. $L a b$ lnvest 2000, 80(2): 159-169.

4I. Ma SL, Sorensen AB, Kunder S, Sorensen KD, Quintanilla-Martinez L, Morris DW, Schmidt J, Pedersen FS: The Icsbp locus is a common proviral insertion site in mature B-cell lymphomas/plasmacytomas induced by exogenous murine leukemia virus. Virology 2006, 352(2):306-318.

42. Yamada Y, Matsushiro H, Ogawa MS, Okamoto K, Nakakuki Y, Toyokuni S, Fukumoto M, Hiai H: Genetic predisposition to pre-B lymphomas in SL/Kh strain mice. Cancer Res 1994, 54(2):403-407.

43. Johansson FK, Brodd J, Eklof C, Ferletta M, Hesselager G, Tiger CF, Uhrbom L, Westermark B: Identification of candidate cancercausing genes in mouse brain tumors by retroviral tagging. Proc Natl Acad Sci USA 2004, I 0 I (3 I): I I 334 - I | 337

44. Ikeda T, Shibata J, Yoshimura K, Koito A, Matsushita S: Recurrent HIV-I integration at the BACH2 locus in resting CD4+ T cell populations during effective highly active antiretroviral therapy. J Infect Dis 2007, 195(5):716-725.

45. Bardwell VJ, Treisman R: The POZ domain: a conserved protein-protein interaction motif. Genes Dev 1994, 8(14): 1664-1677.

46. Zollman S, Godt D, Prive GG, Couderc JL, Laski FA: The BTB domain, found primarily in zinc finger proteins, defines an evolutionarily conserved family that includes several developmentally regulated genes in Drosophila. Proc Natl Acad Sci USA 1994, 91 (22): |07|7-|072|.

47. Deweindt C, Albagli O, Bernardin F, Dhordain P, Quief S, Lantoine D, Kerckaert JP, Leprince D: The LAZ3/BCL6 oncogene encodes a sequence-specific transcriptional inhibitor: a novel function 
for the BTB/POZ domain as an autonomous repressing domain. Cell Growth Differ 1995, 6(I 2): I495-I503.

48. Kang MI, Kobayashi A, Wakabayashi N, Kim SG, Yamamoto M: Scaffolding of Keapl to the actin cytoskeleton controls the function of $\mathrm{Nrf2}$ as key regulator of cytoprotective phase 2 genes. Proc Natl Acad Sci USA 2004, I 0 I(7):2046-205I.

49. Ziegelbauer J, Shan B, Yager D, Larabell C, Hoffmann B, Tjian R: Transcription factor MIZ-I is regulated via microtubule association. Mol Cell 200I, 8(2):339-349.

50. Furukawa $\mathrm{M}, \mathrm{He} \mathrm{Y}$, Borchers $\mathrm{C}$, Xiong $\mathrm{Y}$ : Targeting of protein ubiquitination by BTB-Cullin 3-Rocl ubiquitin ligases. Nat Cell Biol 2003, 5(I I): I00I-1007.

5I. Geyer R, Wee S, Anderson S, Yates J, Wolf DA: BTB/POZ domain proteins are putative substrate adaptors for cullin 3 ubiquitin ligases. Mol Cell 2003, I 2(3):783-790.

52. Pintard L, Willis JH, Willems A, Johnson JL, Srayko M, Kurz T, Glaser S, Mains PE, Tyers M, Bowerman B, et al.: The BTB protein MEL26 is a substrate-specific adaptor of the CUL-3 ubiquitinligase. Nature 2003, 425(6955):3।I-316.

53. Xu L, Wei Y, Reboul J, Vaglio P, Shin TH, Vidal M, Elledge SJ, Harper JW: BTB proteins are substrate-specific adaptors in an SCFlike modular ubiquitin ligase containing CUL-3. Nature 2003, 425(6955):316-32|.

54. Stogios PJ, Downs GS, Jauhal JJ, Nandra SK, Prive GG: Sequence and structural analysis of BTB domain proteins. Genome Biol 2005, 6(I0):R82.

55. Ochiai K, Muto A, Tanaka H, Takahashi S, Igarashi K: Regulation of the plasma cell transcription factor Blimp-I gene by Bach2 and Bcl6. Int Immunol 2008, 20(3):453-460.

56. Olsen HS, Lovmand S, Lovmand J, Jorgensen P, Kjeldgaard NO, Pedersen FS: Involvement of nuclear factor I-binding sites in control of Akv virus gene expression. J Virol 1990, 64(9):4I52-4I6I.

57. Ethelberg S, Hallberg B, Lovmand J, Schmidt J, Luz A, Grundstrom T, Pedersen FS: Second-site proviral enhancer alterations in lymphomas induced by enhancer mutants of SL3-3 murine leukemia virus: negative effect of nuclear factor I binding site. J Virol |997, 7 I (2): I | 96- | 206

58. Ethelberg S, Sorensen AB, Schmidt J, Luz A, Pedersen FS: An SL3-3 murine leukemia virus enhancer variant more pathogenic than the wild type obtained by assisted molecular evolution in vivo. J Virol I 997, 7 I ( I 2):9796-9799.

59. Ethelberg S, Tzschaschel BD, Luz A, Diaz-Cano SJ, Pedersen FS, Schmidt J: Increased induction of osteopetrosis, but unaltered lymphomagenicity, by murine leukemia virus SL3-3 after mutation of a nuclear factor I site in the enhancer. I Virol 1999, 73(1 2): 10406-104I5.

60. Lund AH, Schmidt J, Luz A, Sorensen AB, Duch M, Pedersen FS: Replication and pathogenicity of primer binding site mutants of SL3-3 murine leukemia viruses. J Virol 1999, 73(7):6I17-6I22.
Publish with Bio Med Central and every scientist can read your work free of charge

"BioMed Central will be the most significant development for disseminating the results of biomedical research in our lifetime. "

Sir Paul Nurse, Cancer Research UK

Your research papers will be:

- available free of charge to the entire biomedical community

- peer reviewed and published immediately upon acceptance

- cited in PubMed and archived on PubMed Central

- yours - you keep the copyright
BioMedcentral 